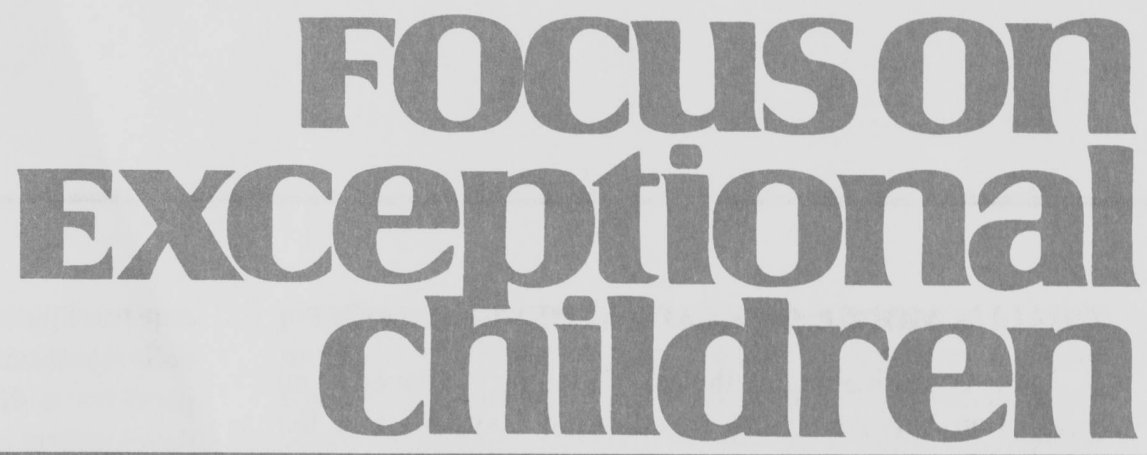

\title{
Literacy Instruction for Secondary Students With Disabilities
}

\author{
Kimber W. Malmgren and Beverly J. Trezek
}

While the professional literature and discourse has continually reinforced the importance of building and strengthening the reading skills of young children, it has long overlooked the importance of literacy instruction at the secondary level, particularly for adolescents who still struggle with reading. Recent initiatives aimed at improving the reading skills of the nation's youth (e.g., Reading First, No Child Left Behind) have resulted in improvements in skills across learners in the early grades; however, the same improvements have not been realized for adolescents. According to the recent National Assessment of Education Progress (NAEP), there was no significant change in the percentage of readers considered proficient in eighth grade from 1992-2007, whereas the percentage of proficient readers in fourth grade rose significantly over the same period of time (Lee, Grigg, \& Donahue, 2007). Compounding the problem, remedial support for literacy is typically provided only at the elementary school level. Consequently, students who enter secondary school still struggling with reading tend to continue to struggle throughout their middle and high school years (Deshler, Palincsar, Biancarosa, \& Nair, 2007; Hasselbring \& Goin, 2004).

In a recent meta-analytic review of interventions for adolescent struggling readers, Scammacca et al. (2007) offered several implications for practice. First, and perhaps most important, the authors indicated that adolescence is not too late to intervene and even older students with learning disabilities benefit from targeted interventions at both the word and text level. Specifically, interventions that focus on word study, developing word meanings and concepts as well as comprehension strategies are appropriate and beneficial for adolescent struggling readers.

Adolescents who struggle to read have unique needs. Recent research suggests components of effective reading instruction as defined by the National Reading Panel (NRP) which we have situated within Chall's (1996) interactive model of reading development. We summarize Chall's model and the components of effective reading instruction detailed in the NRP, followed by a summary of several effective interventions focused on the development of these components at the secondary (i.e., middle and high school) level. Additionally, we provide readers with information about additional resources for improving literacy instruction for struggling secondary readers.

Dr. Malmgren is an associate professor of Special Education at the University of Wisconsin-Madison. Dr. Trezek is an assistant professor of Literacy and Specialized Instruction at DePaul University in Chicago. 


\section{CHALL'S MODEL OF READING DEVELOPMENT}

In the cognitive model, the act of reading is viewed as an interaction between a text-based symbol system and the mind of the reader (Adams, 1990; Chall, 1996). A cognitive information processing model of reading development situates reading as an interactive process involving text, a reader, and the reading context. Within this model, both bottom-up (word identification) and top-down (comprehension) skills are presumed to be simultaneously engaged during reading. This model promotes a balanced view of literacy instruction calling for instructional activities that emphasize both word identification and comprehension skills.

Chall's (1996) stages of reading development-presumed to apply similarly to developing readers of any ageprovide a framework for understanding key skills needed at each phase of development. The stages of reading development delineated by Chall are hierarchical in nature, ranging from pre-reading (where learners collect information about the world around them mainly from contextual clues) to the

\section{Focuson
Exceptional children}

ISSN 0015-511X FOCUS ON EXCEPTIONAL CHILDREN (USPS 203-360) is published monthly except June, July, and August as a service to teachers, special educators, curriculum specialists, administrators, and those concerned with the special education of exceptional children. This publication is annotated and indexed by the ERIC Clearinghouse on Handicapped and Gifted Children for publication in the monthly Current Index to Journals in Education (CIJE) and the quarterly index, Exceptional Children Education Resources (ECER). The full text of Focus on Exceptional Children is also available in the electronic versions of the Education Index. It is also available in microfilm from Serials Acquisitions, National Archive Publishing Company, P.O. Box 998, Ann Arbor, MI 48106-0998. Subscription rates: individual, \$48 per year; institutions, \$66 per year. Copyright (C) 2009, Love Publishing Company. All rights reserved. Reproduction in whole or part without written permission is prohibited. Printed in the United States of America. Periodical postage is paid at Denver, Colorado. POSTMASTER: Send address changes to:

Love Publishing Company

Executive and Editorial Office P.O. Box 22353

Denver, Colorado 80222

Telephone (303) 221-7333

\section{EDITORIAL BOARD}

Lisa Dieker
University of Central Florida

Marleen Pugach

University of Wisconsin-Milwaukee
Carrie E. Watterson

Senior Editor
Paula Maccini University of Maryland construction and reconstruction stage (where readers critically synthesize texts for a purpose). While Chall's model provides a hierarchical structure for understanding the development of reading skills, we turn to the findings of the NRP (2000) to provide guidance in choosing instructional activities that foster the development of the skills laid out by Chall and to organize evidence of promising and effective interventions for struggling secondary readers.

\section{NATIONAL READING PANEL}

In response to a 1997 congressional directive to identify those skills and methods of instruction consistently related to reading achievement, the NRP (2000) was formed. The panel was comprised of reading researchers, representatives of colleges of education, reading teachers, educational administrators, and parents. The panel was charged with reviewing all available reading research with a focus on skills and interventions appropriate to learners in kindergarten through third grade.

The panel initially identified more than 100,000 research studies completed since 1966 . It then reviewed those which (1) measured reading achievement, (2) were generalizable to the larger population, (3) compared approaches to examine their effectiveness, and (4) were deemed high quality. This approach allowed the panel to consider evidence of effectiveness when making recommendations regarding content, methods, and approaches to beginning reading instruction.

In April 2000, the panel submitted a report of its findings to Congress. The resulting National Reading Panel Report suggested five essential components of balanced, effective reading instruction: phonemic awareness, phonics, fluency, vocabulary, and text comprehension. Drawing from the summary report of the NRP entitled, Put Reading FirstThe Research Building Blocks for Teaching Children to Read Kindergarten Through Grade Three (Armbruster, Lehr, \& Osborn, 2001), a brief description of the panel's findings for each of the five components of reading instruction is provided in the following sections. Where appropriate, in order to make our instructional recommendations more pointedly relevant to secondary educators, we augment the NRP's findings with suggestions offered in the report titled Reading Next-A Vision for Action and Research in Middle and High School Literacy: A Report to Carnegie Corporation of New York (Biancarosa \& Snow, 2006).

\section{Phonemic Awareness}

Phonemic awareness refers to a learner's ability to discern that spoken words are composed of small units of sound, or phonemes. The words she (/sh//e/) and he (/h//e/), for example, each contain two phonemes, whereas the words 
cat $(/ \mathrm{cl} / \mathrm{a} / \mathrm{/t} /)$ and fish $(/ \mathrm{fl} / \mathrm{i} / / \mathrm{sh} /)$ contain three phonemes. Phonemic awareness activities are designed to teach children how to manipulate phonemes in oral language. Instruction in phonemic awareness includes teaching students that a) words can have the same beginning or ending sound (alliteration and rhyme), b) words can be divided into parts, and c) word parts can be blended to form words.

Numerous studies have explored the role that phonemic awareness plays in reading acquisition. Correlational studies indicate that students' phonemic awareness skills and knowledge of letters prior to entering school are the two best predictors of how well those students will learn to read in their first two years of formal instruction (Armbruster et al., 2001; McGuinness, 2004, 2005). This compilation of evidence underscoring the importance of phonemic awareness in early reading achievement is the basis for the NRP's inclusion of phonemic awareness studies in their review of the literature.

After reviewing the evidence, the panel concluded that phonemic awareness instruction and activities are an essential component of reading instruction. They reported that systematic and explicit instruction in phoneme manipulation significantly improves students' reading skills and is highly effective across learners of a wide range of ages and grade levels. Once learners can manipulate phonemes in spoken syllables and words, they are prepared to benefit from instruction that focuses on teaching the linkages between spoken sounds and written symbols, commonly referred to as phonics instruction (Armbruster et al., 2001; McGuinness, 2004, 2005).

\section{Phonics}

Unlike phonemic awareness instruction, which focuses primarily on manipulating sounds in oral language, phonics instruction concentrates on teaching the linkages between spoken sounds (phonemes) and written symbols (graphemes). Therefore, phonics instruction teaches children to relate phonemes to graphemes in order to form letter-sound relationships. According to the findings of the NRP, phonics instruction is beneficial for all students in kindergarten through sixth grade and is particularly efficacious for children having difficulty learning to read. In their review of the research, the panel found that the evidence supporting phonics instruction, similar to the evidence supporting phonemic awareness instruction, is so solid that the panel recommends that it become an integral component of reading instruction (Armbruster et al., 2001; McGuinness, 2004, 2005).

Specifically, the panel endorsed the use of systematic phonics instruction, which is characterized as teaching a planned sequence of phonics elements in a particular order. For children experiencing difficulty in learning to read, the panel found that a combination of systematic and synthetic phonics produced the best results when compared to other methods. Synthetic phonics instruction involves teaching students to translate letters to sounds to form recognizable words by providing explicit instruction in blending. Mastering phonics skills allows children to progress to reading words, sentences, and short passages. Once they begin to use phonics skills to read sentences and passages, reading fluency can be integrated into instructional activities (Armbruster et al., 2001; see also the discussions in McGuinness, 2004, 2005).

\section{Fluency}

According to the NRP, fluency is the ability to read accurately, quickly, and with proper expression. When reading silently, fluent readers recognize words automatically and are able to group words together in order to gain meaning from text. When reading orally, these same students read as if they are speaking, naturally and with appropriate expression. On the other hand, readers who are unable to read fluently are labored in their reading; they read slowly, unevenly and word-by-word (Armbruster et al., 2001).

Reading fluency is considered an essential reading skill because it provides the critical bridge between word reading and comprehension. Fluent readers, or those with automatic decoding skills, can read words with ease, which frees cognitive energy to focus on meaning. In contrast, less fluent readers who have not acquired automatic decoding skills must focus their cognitive energy on reading individual words; therefore, little energy or attention is available to concentrate on comprehending the text (Armbruster et al., 2001; see also the discussions in McGuinness, 2004, 2005).

The NRP explored two approaches typically used to encourage fluent reading. The first approach was independent silent reading, in which students read on their own with minimal assistance from the teacher. Although independent (or sustained) silent reading is frequently employed in schools, the panel discovered no evidence to support the effectiveness of silent reading for developing fluency (Armbruster et al., 2001). The second method the panel investigated was guided repeated oral reading. This practice, proving to be more effective in developing fluency according to the panel's review, involves having students engage in repeated oral reading of relatively short passages (100-200 words). A variety of repeated reading strategies (e.g., student-adult, choral, tape-assisted, and partner reading) as well as readers' theatre activities were identified as having a positive effects on developing reading fluency.

\section{Vocabulary}

Vocabulary knowledge can be divided into oral vocabulary and reading vocabulary. A learner's oral vocabulary is composed of the words he or she uses and recognizes in spo- 
ken language. Reading vocabulary, on the other hand, refers to the words a learner recognizes in print. Both oral and reading vocabulary instruction are important elements of effective reading instruction. Struggling (or beginning) readers often have difficulty reading words that are not part of their working oral vocabulary. Instruction geared toward bolstering oral vocabulary can directly assist in developing this skill. Additionally, readers can deduce or infer the meaning of unknown words in text when they are familiar with the majority of the other words in the text passage (Armbruster et al., 2001; Stahl \& Nagy, 2006). Thus, instruction in both oral and reading vocabulary can enhance learners' comprehension of texts.

According to the findings of the NRP, vocabulary should be taught using both indirect and direct instructional strategies. Indirect vocabulary instruction involves the acquisition of new words through engaging in conversations with adults, listening to stories being read, and reading extensively on one's own. In addition to indirect vocabulary instruction, the panel recognized that some vocabulary must be directly taught. Direct vocabulary instruction is particularly important for students who lack prerequisite oral language skills and who are unable to read extensively on their own. However, for all students, direct vocabulary instruction is essential for content-specific words and difficult words that represent complex concepts that are not part of the students' everyday experiences (Armbruster et al., 2001).

The NRP suggested two methods of direct vocabulary instruction: specific word instruction and word learning strategies. Specific word instruction provides students with opportunities to develop in-depth knowledge of word meanings prior to encountering these new words in reading selections. Examples of specific word instruction include teaching definitions, synonyms, antonyms, and analogies, and creating connections between newly acquired words and students' background knowledge. Instruction in word learning strategies enables students to use words accurately in their writing and generalize these words to spoken language (Armbruster et al., 2001; Stahl \& Nagy, 2006). Instruction in the use of the dictionary or thesaurus, word parts (i.e., prefixes, suffixes, roots) and context clues are all examples of word learning strategies.

\section{Comprehension}

Comprehension is the ultimate goal of reading, and to be competent readers, students must be both purposeful and active. This active engagement in the reading process is often referred to as metacognition or "thinking about thinking." Good readers employ metacognitive strategies to clarify a purpose before reading, monitor comprehension during reading, and reflect after reading. As with the other components of reading instruction, the NRP recommended explicit and direct teaching of comprehension strategies in order to meet the goal of improved and enhanced comprehension. Explicit instruction in comprehension strategies involves direct explanations, modeling, guided practice, and independent application (Armbruster et al., 2001).

The strategies recommended by the panel that have the strongest research base include comprehension monitoring, use of graphic and semantic organizers, answering and generating questions, recognizing story structure, and summarizing. Moreover, these strategies can be utilized and taught at any age or grade level. Although some comprehension strategies may be acquired informally, explicit teaching of how and when to apply comprehension strategies is highly effective in advancing students' reading comprehension abilities (Armbruster et al., 2001; Biancarosa \& Snow, 2006).

\section{Computer Technology}

Despite the increased availability of computers in classrooms, the NRP (2000) found that there has been relatively little systematic research conducted on using computer technology to deliver reading instruction. Although the panel's review included studies exploring the use of computer technology in vocabulary, word recognition, comprehension, and spelling instruction, the majority of investigations examined either the addition of speech to computer presented text or comprehension software packages. The limited number and diversity of the studies made it difficult for the panel members to provide clear conclusions and offer specific instructional recommendations regarding the use of computer technology to enhance and support reading instruction. However, the panel did offer several implications for practice.

First, the panel suggested that computers can be used for some instructional tasks, and, at the very least, the addition of computer technology in reading instruction provides students with opportunities to engage in reading more frequently than with conventional instruction alone. The panel also indicated that despite the experimental evidence of its effectiveness, the use of multimedia, hypertext, and hypermedia appear to have great potential, particularly as it relates to motivating students to engage in reading. Finally, the use of word processing appeared to be a useful addition to reading instruction since reading and writing instruction often occur in conjunction with one another (NRP, 2000). In the following sections, a summary of effective interventions for secondary readers focuses on developing phonemic awareness, phonics, fluency, vocabulary, and comprehension skills, including interventions incorporating computer technology. 


\section{INTERVENTION STRATEGIES}

\section{Phonics and phonemic awareness}

While most research that documents phonemic awareness and phonics skill development and assesses the impact of interventions aimed at these critical areas is conducted with participants at the early elementary grades, the importance of phonemic awareness and phonics for struggling adolescent readers should not be overlooked. One strategy for students who struggle with reading at the secondary level is to take a compensatory approach, to forego direct instruction of basic skills in order to devote valuable instructional time to functional literacy. However, there is evidence that focusing on phonemic awareness and phonics, even for secondary students, holds promise.

With this assertion in mind, Bhattacharya and Ehri (2004) examined the effects of an intervention in which they taught sixth-ninth graders, whose grade-equivalent reading levels were at the third-fifth grades, to break words into syllables and match the spellings of those syllables to their pronunciations. The intervention was referred to as "graphosyllabic analysis" and resulted in improvements in the decoding of novel words, in the ability to segment words into syllables, and in the ability to identify subtle misspellings of common words where the erroneous letters were embedded in the middle of the words. This last outcome is important in that students with reading disabilities have been shown to attend primarily to the beginning and endings of words, causing them to make mistakes when sounding out polysyllabic words (Ehri \& Saltmarsh, 1995).

In a recent summary of evidence-based reading instructional strategies for older students, Roberts, Torgesen, Boardman, and Scammacca (2008) contended that many struggling adolescent readers can typically decode singlesyllable words. Therefore, Roberts et al. suggest utilizing interventions that place an emphasis on improving readers' abilities to decode multisyllabic words. Suggested interventions include teaching students to analyze parts of words (e.g., prefixes, suffixes) and to break difficult words into smaller, more familiar chunks. These instructional strategies are referred to by Roberts et al. as "word study" interventions and are presented as methods that lead adolescent readers to be more effective decoders. Word study interventions, though not clearly linked to gains in comprehension, have been associated with moderate positive effects for struggling adolescent readers, including those with learning disabilities (Scammacca et al., 2007).

\section{Fluency}

As emphasized by the NRP (2000), the ability to read fluently-quickly, accurately, and with proper expression-is related to the ability to make meaning of text. Reading slowly and inaccurately impedes a reader's comprehension in several ways. For one, the reader may simply be misinformed due to inaccurate reading of the text. In addition, dysfluent reading impedes comprehension by making it difficult for the reader to make sense of, or even remember, complete sentences. These problems can be compounded for secondary age readers, who are required to read longer passages in shorter and shorter amounts of time as they progress through the grades and are exposed to more complex literature and content area texts.

One strategy named specifically by the NRP (2000) in their review of effective fluency building strategies is the use of repeated readings. Research has shown repeated reading to be an effective strategy with struggling readers (with and without identified learning disabilities) at both the middle (see Homan, Klesius, \& Hite, 1993) and high school levels (Valleley \& Shriver, 2003). Repeated reading refers to the strategy of having students read specific passages of text over and over again. Passages should be at the students' instructional level and should contain between 200-400 words.

During repeated reading, the interventionist typically records the number of words read correctly in one minute (WCPM) by each student on his or her first reading of the passage. The student is then asked to read the passage again. This procedure is repeated either a set number of times, (e.g., 3 times per passage) or to a set criterion (e.g., the passage will be read until three separate gains in WCPM have been recorded or until the student demonstrates a $10 \%$ gain in fluency). Choosing to have students read a set number of times is the simpler option, but having students read to a set criterion has been shown to be significantly more effective at promoting gains in fluency as well as in comprehension (Therrien, 2004). If a set criterion approach is taken, the interventionist should also set a cut-off for a maximum number of times that a student will be required to read a passage to reduce the likelihood that the student will get frustrated. In their work with adolescents in a residential treatment center, Valleley and Shriver (2003) chose a maximum of ten readings per passage in order to minimize reader frustration. The costs and benefits of these different approaches are likely obvious: Choosing to have students read passages a set number of times is easier to implement, but having the student read to a set criterion ensures that improvement is being realized during the intervention.

Another consideration is the choice of interventionist. While repeated reading interventions may be implemented using peer dyads, the benefits of repeated reading for both fluency and comprehension are greatly enhanced when an adult oversees the repeated reading intervention (Therrien, 2004). This adult can be the teacher, a paraprofessional, or a tutor. Fortunately, repeated reading is a relatively simple 
intervention to implement. Once the teacher has selected 200-400 word reading passages at the student's instructional level, made them available for the interventionist and student to use, and has taught the interventionist the routine, the intervention sessions are quick and easy to carry out.

One final consideration to enhance the use of repeated readings is "cueing" the student. Cueing refers to a prompt that the interventionist gives to the student right before he or she begins to read the passage. When the interventionist cues the student to read "carefully" or to focus on comprehending the passage while reading, the effect on the student's resulting comprehension is greater than if the interventionist cues the student to read as "quickly" as possible. According to research, cueing the student to focus on reading for both comprehension and fluency has a slightly less powerful impact on comprehension but an even greater impact on fluency (Therrien, 2004). Teachers should keep these distinctions in mind when designing repeated reading interventions.

While implementing repeated readings has resulted in fluency gains for adolescent readers, it is important to note that repeated reading should not be used as the sole intervention to address the needs of older struggling readers. Indeed, Edmonds et al. (2009) pointed out that the positive relationship between increased fluency and improved comprehension seems to diminish as students reach the secondary grades. Interventions that target word reading skills (i.e., phonics) are important for older students who still struggle with decoding, and explicit comprehension instruction is an essential component of reading instruction for all struggling adolescent students.

\section{Vocabulary}

Because adolescents who struggle with reading are not as likely as their proficient counterparts to choose to read widely, frequently, and for sustained periods (Baker, Simmons \& Kame'enui, 1998), acquisition of new vocabulary is a skill that secondary special educators must focus on in their work. Compounding the challenge for special educators is the likelihood that one category of struggling readers, those with identified learning disabilities, require more exposures to a word (i.e., 12 or more) before it becomes part of their working vocabulary (McKeown, Beck, Omanson, \& Pople, 1985). Several approaches to increasing vocabulary show promise for secondary students with disabilities. One such commonly used approach is the direct instruction of new words. When exposing students to new content-specific vocabulary, the use of simple definitions is recommended, as is thoughtful consideration of dictionary use in the classroom. Similarly, if definitions are provided, care should be taken that definitions are succinct and resonate with the students.
Along with simple definitions, teachers should provide students with examples and nonexamples and use graphic organizers when appropriate. When used in vocabulary instruction, graphic organizers are typically designed to include a space in the center for the target word, surrounded by links to additional spaces in which students can make connections to the central word. These additional spaces might call for elements such as a drawing pertaining to the word, the word used in a sentence, antonyms or synonyms for the word, and a definition in the student's own words (Phillips, Foote, \& Harper, 2008). Although graphic organizers are a popular strategy to develop vocabulary skills, the use of graphic organizers for vocabulary instruction alone has not been clearly shown to have a direct effect on increased comprehension. Therefore, it may be useful for teachers to give students guidance and practice in applying graphic organizers to new texts and to expand instruction to include comprehension skill instruction so that this strategy can have a more lasting impact. With these caveats in mind, graphic organizers can be viewed as one potentially helpful intervention. All of these strategies, in addition to the simple act of repeated exposure (Stahl \& Fairbanks, 1986), have been linked to growth in vocabulary for adolescents.

Given the competing demands on teacher time and student energy, as well as the importance of vocabulary acquisition for students with disabilities who struggle with reading, choosing words for focused instruction is an important consideration. Certainly, while educators need to emphasize vocabulary development, they also need to allot time to phonics, fluency, and comprehension instruction. The choice of which words to emphasize becomes an exercise in efficiency. One source of word lists is from content area texts. However, teachers should approach these lists with an eye toward maximizing benefit. Priority should be given to words that are likely to appear in many contexts. Given that students with disabilities require numerous exposures to a word before it becomes a part of their working vocabulary, emphasizing words that might appear in multiple contexts allows the teacher to maximize opportunities for multiple exposures. Similarly, choosing content-specific words that appear repeatedly in a science or social studies chapter might have the same effect.

Beck, McKeown, and Kucan (2002) categorize words as Tier One, Tier Two, or Tier Three. Tier One are basic words, such as "baby" or "fun," that school-aged children rarely require instruction to master. Tier Three words are low frequency words that are limited to specific domains (e.g., "phalanges" or "hydrology"). Tier Two words are those that appear (or are heard) repeatedly in multiple contexts. Additionally, Tier Two words are associated with concepts that a student already knows. A student would be able to explain a Tier Two word using words already in his or her 
working vocabulary. The addition of the new word would thus allow the student more precision or sophistication when communicating. Beck et al. suggest focusing on Tier Two words in order to have the greatest impact on vocabulary development.

In addition, the direct instruction of word lists and wordstudy interventions, described earlier in the section on phonics instructional strategies, can also have the added effect of increasing vocabulary by giving students tools to break apart and decipher smaller chunks of unknown words that they encounter in text. Knowing the meaning of affixes (i.e., prefixes and suffixes) such as "anti-" or "-ly" can assist adolescents' acquisition of new vocabulary.

Another indirect approach to increasing vocabulary is referred to as the development of word consciousness. While largely unnoticed in special education, Ebbers and Denton (2008) recently drew attention to this strategy as holding promise for adolescents with reading difficulties. Word consciousness refers to our overall metalinguistic awareness. Adult readers and typical adolescent learners recognize patterns in words encountered in text and spoken in everyday life. A "word conscious" student might notice the overlap between the word "conquistador," described in a world history textbook, and "conquest" as referred to in a fantasy computer game. Word consciousness is "crucial to learners' success in expanding the breadth and depth of their word knowledge over the course of their lifetimes" (Graves $\&$ Watts-Taffe, 2002, p. 145). Drawing attention to word patterns as they present themselves in classroom discourse and printed materials also allows teachers to employ indirect vocabulary instruction to enhance word consciousness.

\section{Comprehension}

Making sense of what we read is widely acknowledged as a primary objective of reading. Assisting adolescents who struggle to read with this important skill is a complex endeavor, best achieved by employing multiple instructional approaches. One approach that has been shown to be effective for increasing the comprehension skills of adolescent readers is teaching them to understand and recognize text structures. Text structures are the semantic and syntactic ways that authors organize written information. Being familiar with text structures helps adolescents better understand what they are reading - giving them schema to draw on when processing new text. Text structures vary dramatically between narrative (i.e., fiction) and expository (i.e., nonfiction) texts and should be taught as distinct skills. Familiarizing students with story grammar elements and directing them to identify elements such as character, setting, conflict, resolution, and theme have been shown to increase their comprehension of narrative texts. Although story grammar elements are typically part of the elementary language arts curriculum, struggling adolescent readers still benefit from instruction in this area. Text structures that apply to expository texts are less often examined by researchers than those addressing narrative texts, even though strategies to aide the comprehension of expository texts are arguably more important for adolescents who are asked to process content text daily in their secondary classrooms.

One instructional approach used to address narrative story structure with adolescents is the Embedded StoryStructure (ESS) Routine (Faggella-Luby, Schumaker, \& Deshler, 2007). The story structure strategy included in the ESS involves a graphic organizer that students use to record specific elements and events from a story. Each story element recorded on the graphic organizer is then associated with picture cue (a mnemonic) which students can then utilize when they complete the Story Structure Diagram portion of the graphic organizer. For example, the "Time" question on the graphic organizer (i.e., "When does the story take place?") is associated with a small clock icon. The "Climax" question (i.e., "Which decision or event is the climax (or turning point)?" is associated with a small ticking bomb icon. When the students finish recording all of the story elements on the graphic organizer, they then use the picture cues (icons) to complete the Story Structure Diagram, further reinforcing the students' awareness of the story's structure, which strengthens comprehension. The ESS also includes a self-questioning strategy that students are directed to use prior to reading a story as well as a summary writing strategy that results in a four-sentence summary of the passage in question.

The use of graphic organizers is another helpful comprehension-building strategy that teachers of adolescents can employ. However, it is important to note that some studies of the effectiveness of graphic organizers have shown that they improve students' ability to recall information recorded on the organizer more than they improve general comprehension. Vallecorsa and deBettencourt (1997), for example, conducted a study in which they directly taught seventh grade students with learning disabilities to use a story map that prompted the students to record and comment on eight story elements (e.g., setting, goal/problem, starter event). At the completion of the intervention phase, all participating students could name the story elements of a given narrative text with more consistency. However, this success did not transfer to the students' ability to later write about the story. It appears that teaching students to use story maps or other similar graphic organizers is useful, but not sufficient, to ensure meaningful comprehension.

Interventions that are multifaceted, targeting multiple skills simultaneously, intuitively hold appeal for enhancing comprehension skills. Peer Assisted Learning Strategies 
(PALS), originally developed for use with younger students, is one such intervention (Fuchs, Fuchs, \& Kazdan, 1999). PALS is a peer-mediated intervention that is implemented most easily in settings that serve a heterogeneous group of learners. The PALS intervention is designed to be a supplementary reading activity, and it consists of three main instructional elements that students complete together in pairs in which one reader is stronger than the other. Elements of the intervention include: "Partner Reading," where students take turns reading passages aloud to each other then briefly summarize what they read; "Paragraph Shrinking," where students stop after each paragraph to identify the main idea; and "Prediction Relay," in which students read longer passages (e.g., half a page), pausing at the end of each section to predict what will happen next and then to confirm or disconfirm whether their prediction came true. With the combination of these elements, the PALS intervention allows for modeling, practice, and feedback on the important comprehension skills of summarizing, paraphrasing, and predicting what will happen next in narrative texts. While the effect size associated with gains made by secondary students with disabilities who were exposed to this program is fairly small, it is encouraging that gains in comprehension on a standardized measure of reading comprehension were realized.

In general, secondary teachers of struggling readers-be they reading specialists, language arts instructors, or content area teachers - should teach students to use strategies that can be easily transferred to new texts and literacy demands. Examples of such strategies are teaching students to ask questions about the text, seek clarification for unknown words or concepts, summarize what they have read, and predict what might happen next. Many of these elements are embedded in the intervention strategies described above, as well as in other techniques such as Reciprical Teaching (Palincsar \& Herrenkohl, 2002), and lend themselves well to comprehension of both narrative and expository text.

\section{Technology}

The use of technology to aide instruction is an increasingly viable option for educators, as computer use becomes more prevalent in classrooms. For educators charged with improving the skills of struggling adolescent readers, who often lack motivation to improve their skills, the use of technology in instruction holds promise as a possible motivating strategy. While use of technology in the classroom alone is sometimes motivating and reinforcing, teachers should keep in mind that the most effective technologies are those that allow students to have more opportunities to practice new and targeted skills and those that allow teachers to more easily customize instruction to meet individual learning needs (Biancarosa, 2005).
The Peabody Literacy Lab is one example of a technology-based intervention focused on multiple components of effective reading instruction that has been linked to positive results for adolescents (Hasselbring \& Goin, 2004). This program combines comprehension instruction with wordlevel decoding instruction and opportunities to practice spelling. The program allows for progress monitoring and makes adjustments to each student's content based on the results of that progress monitoring. This kind of real-time tracking and adjustment to instruction is a further advantage of incorporating technology into reading instruction.

Modeling fluent reading is another support that computer programs have the capacity to provide for students during practice. One-on-one modeling is time consuming and impractical for teachers; however, computer programs with speech features are a helpful option for offering individual attention to students (Hasselbring \& Goin, 2004).

Another benefit that technology can bring to reading instruction is providing support to students through hypertext. Hypertext allows students to access additional individualized "on-demand" support through pop-ups that can include definitions and pronunciations of words, background information on new concepts, and, if the software allows, teacher comments and questions. Use of these enhanced hypertext features has been linked to positive effects on secondary students' comprehension of expository text (MacArthur \& Haynes, 1995).

\section{RECOMMENDED INTERVENTION PROGRAMS}

Adolescent struggling readers can benefit from targeted interventions at both the word and text level (Scammacca et al., 2007). Therefore, it is critical for teachers to select effective curricular interventions specifically designed for secondary readers and tailored to meet their particular instructional needs. Researchers at the Florida Center for Reading Research (FCRR, 2006) have conducted an extensive review of comprehensive and supplemental reading intervention programs to determine the extent to which the curriculum addresses the five components of effective instruction recommended by the NRP (i.e., phonemic awareness, phonics, fluency, vocabulary, and comprehension). In this section, we provide a summary of their review.

Using a one to three rating system $(+,++,+++)$, raters at the FCRR (2006) indicated whether few aspects $(+)$, most aspects (++), or all aspects (+++) of the component are taught and/or practiced within the curriculum. Reviewed programs were also organized by type such as those designed for students in third grade and above, technologybased programs, and programs that can be implemented by a tutor or mentor. Informational notes for each program were also included as part of the review. These notes ranged 
from information regarding the focus of the program (e.g., phonics, fluency, vocabulary) to guidelines for implementing the curriculum (e.g., extensive professional development or school-wide implementation required). As our focus is on describing effective and promising strategies to address the needs of struggling adolescent readers, we will summarize the findings obtained by the FCRR for comprehensive and supplemental programs intended for students in third grade and higher.

Comprehensive reading intervention programs are designed to focus on all five components of reading instruction. In providing summary information about comprehensive programs, we include programs that received rankings of two or three from the FCRR on at least some of the components. For example, the Academy of Reading Program received ratings of two on the phonemic awareness, phonics, and fluency components, but ratings of one in the categories of vocabulary and comprehension. Programs that received the highest overall ratings (threes on all five components) include Corrective Reading, Language!, Project Read, Reach, and The Reading Edge. Programs receiving strong ratings (twos or threes on all five components) include HOSTS, Kaplan SpellRead, Lexia Reading, Orchard, The Reading Edge, S.P.I.R.E., and Wilson Reading System. A summary of the ratings for these and other comprehensive reading intervention programs developed for students in third grade or higher can be found in Table 1 .

Programs in the supplemental reading intervention category focus on one or more component of instruction rather than all five. For example, the LiPS program focuses on phonemic awareness and phonics instruction, but not fluency, vocabulary, or comprehension skills development. The supplemental program for students in third grade and higher that had strong ratings (two or three) in phonemic awareness was Fast Forward Language, while the LiPS and Seeing Stars programs had strong ratings for both the phonemic awareness and phonics components. Discover Intensive Phonics for Yourself, My Reading Coach, and Phonics for Reading were the programs that received strong ratings in phonics according to the FCRR (2006) review.

For the fluency component, the Great Leaps, Read Naturally, Six-Minute Solution, TUNEin to Reading, and Wilson Fluency/Basic programs received strong ratings from the FCRR team. In the area of vocabulary, Building Vocabulary Skills received strong ratings while Questioning the Author and Visualizing and Verbalizing were rated highly in the area of comprehension. Multi-component supplemental reading interventions that received strong ratings from the FCRR (2006) included the Failure Free Reading (fluency and vocabulary), Read On! and Read XL

TABLE 1

Summary of Comprehensive Reading Intervention Program Ratings

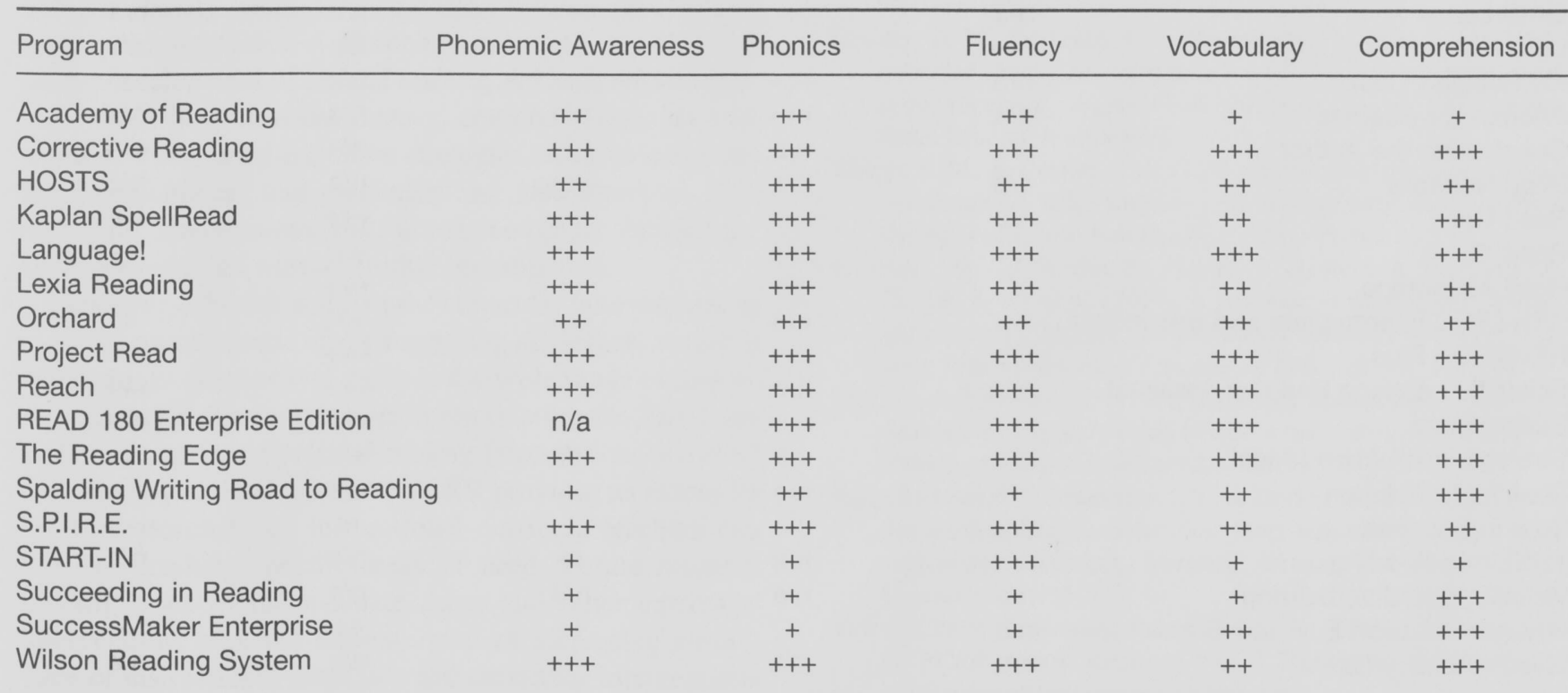


(vocabulary and comprehension), REWARDS Intermediate and Secondary (phonics, fluency, and vocabulary), Strategic Instruction Model (phonics, vocabulary, and comprehension), Scientific Learning Reading Assistant, Soar to Success, and Voyager Passport (fluency, vocabulary, and comprehension), and Reading Advantage and REWARDS Plus (phonics, fluency, vocabulary, and comprehension). A summary of the ratings for these and other supplemental reading intervention programs designed for students in third grade or higher can be found in Table 2 . We encourage educators to explore the full review of comprehensive and supplemental reading intervention programs available at http://www.fcrr.org as well as other web-based resources on reading offered through the Access Center http://www.k8accesscenter.org/index.php, the American Federation of Teachers http://www.aft.org/, and the What Works Clearinghouse http://ies.ed.gov/ncee/ $\mathrm{wwcl}$.

\section{CONCLUSION}

Secondary teachers working with adolescents who still struggle with basic literacy tasks are routinely faced with the dual challenge of motivating students to stay invested in the learning process and also guiding them to acquire elusive skills. Teachers who offer remedial reading instruction at the secondary level have a critically important job-with historically little guidance from research on effective practices. Fortunately, the increased emphasis on reading instruction at the early grades that has been central to educational reforms in the last decade is now starting to be felt at the secondary level as well. While findings from the NRP pertain most directly to the teaching of reading in grades $\mathrm{K}-3$, the application and expansion of the NRP's findings to reading instruction at the secondary level is starting to be systematically explored.

The NRP identified five essential elements of balanced reading instruction that parallel the developmental stages of

TABLE 2

Summary of Supplemental Reading Intervention Program Ratings

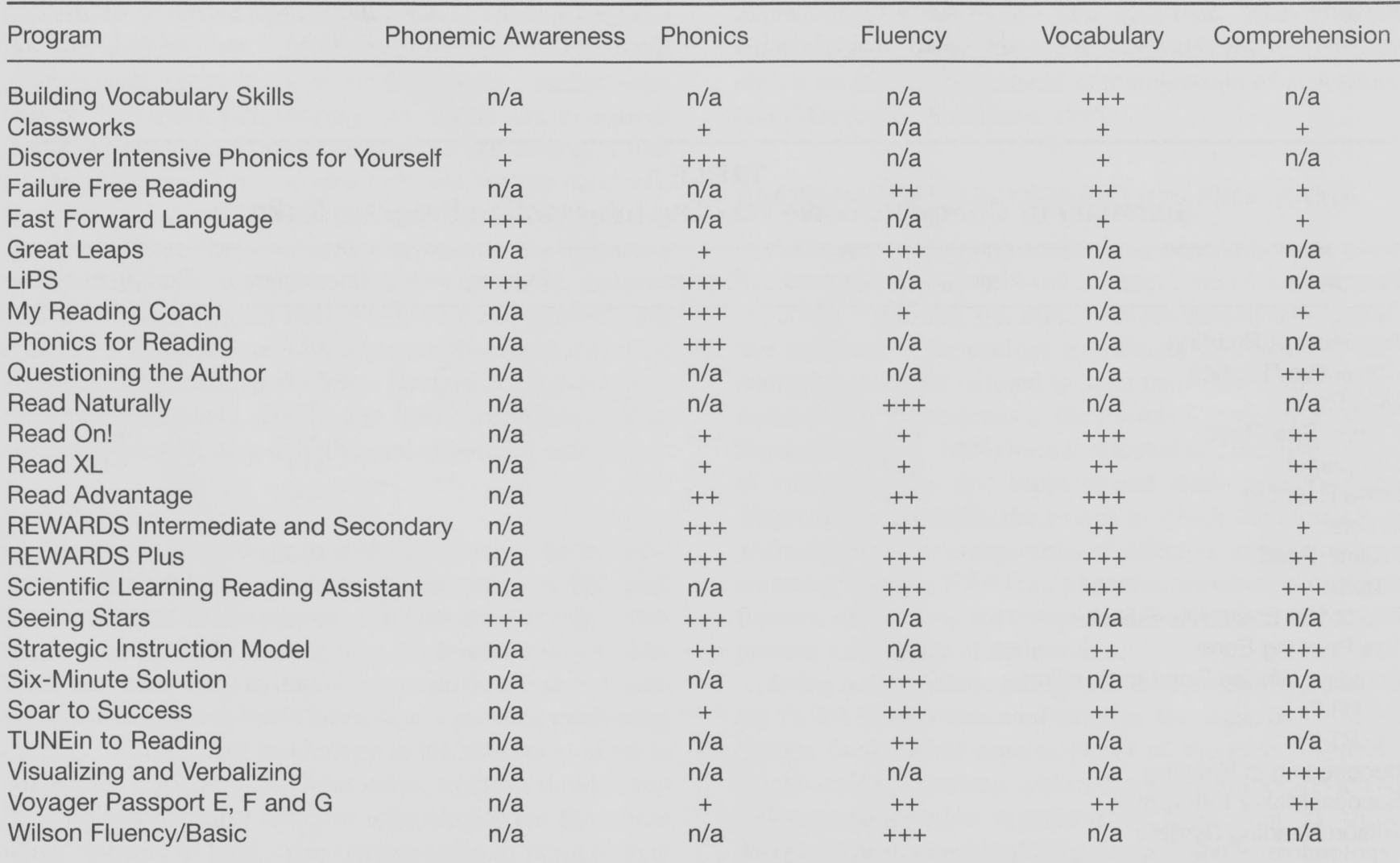


the cognitive information processing model: phonemic awareness, phonics, fluency, vocabulary, and comprehension. In the context of the cognitive information processing model, we believe that instruction focused on the development of these skills is not only appropriate for the adolescent struggling reader but also imperative in order to facilitate progress in specific areas and demonstrate gains in overall reading ability. Although the research base applied to adolescents is still budding for some of the areas of reading instruction recommended by the NRP, we can translate some research findings into practice. For example, evidence indicates that struggling secondary readers can improve their ability to decode, segment, and spell words when provided with instruction in graphosyllabic analysis. Similarly, word study interventions are beneficial for teaching adolescents to decode multisyllabic words. Interventions aimed at increasing fluency, such as repeated reading, have been demonstrated to be an effective strategy for struggling readers, both with and without disabilities, at the middle and high school levels.

In vocabulary instruction, which is particularly important for adolescent struggling readers who are less likely to acquire vocabulary by reading independently, teachers must be mindful of the types of words they choose to teach. Pedagogically, direct vocabulary instruction, word-study, and the use of graphic organizers are all strategies proven to be effective to teach vocabulary to the adolescent reader.

In order to further develop the comprehension skills of the adolescent reader, instruction should focus on teaching text structures for both narrative and expository texts. As with vocabulary instruction, research also indicates the use of graphic organizers. Additionally, interventions focusing on the development of several reading skills simultaneously (e.g., word identification, fluency, comprehension) as well as those that embed cognitive strategies, such as questioning, summarizing, and predicting, are also effective. Furthermore, interventions that utilize computer technology show promise and warrant further investigation.

Selecting effective and focused curricular interventions to meet the unique needs of the struggling adolescent reader is necessary to demonstrate gains in the wide range of important literacy skills for this population of students. The comprehensive and supplemental reading interventions reviewed and rated by researchers at the FCRR provides an extensive list of research-based instructional curricula teachers can use to remediate specific areas of need. Future research investigations should evaluate these and other curricular interventions with the ultimate goal of increasing knowledge of instructional strategies and curricular interventions specifically designed and proven efficacious for the adolescent struggling reader. In the meantime, teachers should continue their efforts to provide high quality instruction to these students during the critically important window of secondary school in order to maximize their positive outcomes. We hope the suggestions offered here, as well as the growing body of evidence being generated by other researchers and special education practitioners, will continue to fuel interest and skill in improving the literacy of students with disabilities who struggle with reading.

\section{REFERENCES}

Adams, M. (1990). Beginning to read: Thinking and learning about print. Cambridge, MA: The M.I.T. Press.

Armbruster, B. B., Lehr, F., Osborn, J. (2001). Put reading first: The research building blocks for teaching children to read kindergarten through grade three. Jessup, MD: National Institute for Literacy.

Baker, S. K., Simmons, D. C., \& Kame'enui, E. J. (1998). Vocabulary acquisition: Instruction and curricular basics and implications. In D. C. Simmons \& E. J. Kame'enui (Eds.). What reading research tells us about children with diverse learning needs: Bases and basics (pp. 219-238). Mahwah, NJ: Erlbaum.

Beck, I. L., McKeown, M. G., \& Kucan, L. (2002). Bringing words to life: Robust vocabulary instruction. New York: Guilford.

Bhattacharya, A., \& Ehri, L. C. (2004). Graphosyllabic analysis helps adolescent struggling readers read and spell words. Journal of Learning Disabilities, 37, 331-348.

Biancarosa, G. (2005). After third grade. Educational Leadership, 63(2), 16-22.

Biancarosa, G., \& Snow, C. E. (2006). Reading next-A vision for action and research in middle and high school literacy: A report to Carnegie Corporation of New York (2nd ed.). Washington, DC: Alliance for Excellent Education.

Chall, J. S. (1996). Stages of reading development (2nd ed.). New York: McGraw-Hill.

Deshler, D. D., Palincsar, A. S., Biancarosa, G., \& Nair, M. (2007). Informed choices for struggling readers: A research-based guide to instructional programs and practices. Newark, DE: International Reading Association.

Ebbers, S. M., \& Denton, C. A. (2008). A root awakening: Vocabulary instruction for older students with reading difficulties. Learning Disabilities Research \& Practice, 23(2), 90-102.

Edmonds, M. S., Vaughn, S., Wexler, J., Reutebuch, C., Cable, A., Tackett, K. K., et al. (2009). A synthesis of reading interventions and effects on reading comprehension outcomes for older struggling readers. Review of Educational Research, 79, 262-300.

Ehri, L., \& Saltmarsh, J. (1995). Beginning readers outperform older disabled readers in learning to read words by sight. Reading and Writing: An Interdisciplinary Journal, 7, 295-326.

Faggella-Luby, M., Schumaker, J. S., \& Deshler, D. D. (2007). Embedded learning strategy instruction: Story-structure pedagogy in heterogeneous secondary literature classes. Learning Disability Quarterly, 30, 131-147.

Florida Center for Reading Research (FCRR). (2006). Summary table for FCRR reports. Retrieved June 7, 2009, from http://www.fcrr. org/fcrrreports/creportscs.aspx?rep=supp.

Fuchs, L. S., Fuchs, D., \& Kazdan, S. (1999). Effects of peer-assisted learning strategies on high school students with serious reading problems. Remedial and Special Education, 20, 309-318. 
Graves, M. F., \& Watts-Taffe, S. M. (2002). The place of word consciousness in a research-based vocabulary program. In A. E. Farstrup \& S. J. Samuels (Eds.). What Research Has to Say about Reading Instruction (3rd ed., pp. 140-165). Newark, DE: International Reading Association.

Hasselbring, T. S., \& Goin, L. I. (2004). Literacy instruction for older struggling readers: What is the role of technology? Reading \& Writing Quarterly, 20, 123-144.

Homan, S. P., Klesius, J. P., \& Hite, C. (1993). Effects of repeated readings and nonrepetitive strategies on students' fluency and comprehension. Journal of Educational Research, 87, 94-99.

Lee, J., Grigg, W., \& Donahue, P. (2007). The nation's report card: Reading 2007 (NCES 2007-496). Washington, DC: National Center for Education Statistics, Institute of Education Sciences, U.S. Department of Education. Retrieved November 17, 2008, from http://nces.ed.gov/pubsearch/pubsinfo.asp?pubid=2007496

MacArthur, C. A., \& Haynes, J. B. (1995). Student Assistant for Learning from Text (SALT): A hypermedia reading aid. Journal of Learning Disabilities, 28, 150-159.

McGuinness, D. (2004). Early reading instruction: What science really tells us about how to teach reading. Cambridge, MA: The M.I.T. Press.

McGuinness, D. (2005). Language development and learning to read: The scientific study of how language development affects reading skill. Cambridge, MA: The M.I.T. Press.

McKeown, M. G., Beck, I. L., Omanson, R. C., \& Pople, M. T. (1985). Some effects of the nature and frequency of vocabulary instruction on the knowledge and use of words. Reading Research Quarterly, 20, 522-535.

National Reading Panel (NRP). (2000). Teaching children to read: An evidence-based assessment of the scientific research literature on reading and its implications for reading instruction. Washington, DC: National Institute of Child Health and Human Development.
Palincsar, A. S., \& Herrenkohl, L. R. (2002). Designing collaborative learning contexts. Theory Into Practice, 41, 26-32.

Phillips, D. C. K., Foote, C. J., \& Harper, L. J. (2008). Strategies for effective vocabulary instruction. Reading Improvement, 45(2), $62-68$,

Roberts, G., Torgeson, J. K., Boardman, A., \& Scammacca, N. (2008). Evidence-based strategies for reading instruction of older students with learning disabilities. Learning Disabilities Reearch \& Practice, 23, 63-69.

Scammacca, N., Roberts, G., Vaughn, S., Edmonds, M., Wexler, J., Reutebuch, C. K., et al. (2007). Interventions or adolescent struggling readers: A meta-analysis with implications for practice. Portsmouth, NH: RMC Research Corporation, Center on Instruction.

Stahl, S. A., \& Fairbanks, M. M. (1986). The effects of vocabulary instruction: A model-based meta-analysis. Review of Educational Research, 56, 72-110.

Stahl, S., \& Nagy, W. (2006). Teaching word meanings. Mahwah, NJ; Erlbaum.

Therrien, W. J. (2004). Fluency and comprehension gains as a result of repeated reading: A meta-analysis. Remedial and Special Education, 25, 252-261.

Vallecorsa, A., \& deBettencourt, L. U. (1997). Using a mapping procedure to teach reading and writing skills to middle grade students with learning disabilities. Education and Treatment of Children, 20, 173-188.

Valleley, R. J., \& Shriver, M. D. (2003). An examination of the effects of repeated readings with secondary students. Journal of Behavioral Education, 12(1), 55-76.

\section{PERMISSIONS AND COPYRIGHT}

All rights are reserved. No part of this publication may be reproduced, photocopied, faxed, stored in a retrieval system, or transmitted in any form or by any means, electronic, mechanical, recording or otherwise, without the prior written permission of the publisher.
Back issues are available for sale. Reproduction requires permission and payment of fees. It is illegal and a violation of federal copyright law to reproduce this publication without permission. Direct all inquiries to the permissions editor. 